\title{
Circulating immune complexes and complement levels in relation to the clinical presentation of Nigerian children with acute poststreptococcal glomerulonephritis
}

\author{
I. I. ONYEWOTU AND JENNY MEE
}

From the Department of Medicine and Paediatrics, Ahmadu Bello University Hospital, Zaria, Nigeria

SUMMARY Circulating immune complexes have been detected in the sera of 24 Nigerian children with acute poststreptococcal glomerulonephritis using two methods. There was a significant correlation between levels of soluble complexes, detected in samples taken from patients in the oliguric phase of acute nephritis, and severity of disease, as judged by blood urea levels. Serial estimation of immune complexes was more useful than serial C3 estimation in predicting the onset of anuria in two patients admitted with mild disease who subsequently deteriorated. With one exception. C4 values were normal. Factor B levels were low in $90 \%$ of cases, in keeping with activation of the alternate complement pathway.

Renal damage in poststreptococcal acute glomerulonephritis (AGN) and lupus nephritis is probably mediated through a similar immunopathogenic process involving deposition in renal glomeruli of circulating antibody-non glomerular antigen complexes (Andres et al., 1966; Koffler et al., 1967; Krishman and Kaplan, 1967; Zabrikie, 1971). The finding of cryoglobulins, principally containing IgG, in poststreptococcal AGN lends support to the presence of soluble immune complexes in this disease (McIntosh et al., 1970). Other reports of circulating complexes in AGN have been published by Mohammed et al. (1977) and Sobel et al. (1976). These findings suggest that low levels of C3 in AGN occurred as a result of activation of the classical complement pathway by soluble immune complexes. However, recent evidence obtained from studies of complement components in this disease shows that the situation is more complicated for $\mathrm{Clq}$, and $\mathrm{C} 4$ levels have consistently been reported to be normal (Kohler and ten Bensel, 1969; Lewis et al., 1971; Cameron et al., 1973).

The low C3 usually observed in AGN has been attributed principally to the activity of $\mathrm{C} 3$ nephritic factor (C3NeF) rather than to immune complexes (Lewis et al., 1971). C3NeF is the name given to an

Received for publication 4 January 1978 activity that stabilises the alternate pathway convertase and acts only via this pathway (Williams et al., 1974; Schreiber et al., 1975; Amos et al., 1976). However, this factor occurs mainly in mesangiocapillary glomerulonephritis (MCGN) and only in a small proportion of patients with AGN (Williams et al., 1974). Decreased C3 in AGN has also been related to decreased production, increased turnover, and a combination of both (Alper et al., 1966).

Poststreptococcal AGN is a common disease in Nigerian children. It has long been recognised that it can follow streptococcal infection of the skin as well as the throat (Anthony and Wannamaker, 1967; Potter et al., 1968; Dillon, 1970). A previous report from Zaria shows that AGN associated with skin infection is quite common (Whittle et al., 1973). Our study aims at further investigating the disease in Nigerian children by looking for soluble, circulating immune complexes in the sera of children presenting with acute nephritis, with a view to relating the levels detected to the clinical pattern of the disease.

\section{Patients and methods}

PATIENTS Twenty-four patients presenting at Ahmadu Bello University Hospital, Zaria with the clinical picture of AGN, confirmed by a low serum C3 on admission, and 20 children matched for age and sex with pyoderma but no nephritis were 
studied. Twenty-three other children attending the outpatients department with minor complaints acted as controls. The ages of the patients ranged from 2 to 10 years, but the majority were between 6 and 9 years. Only patients who gave a history of an acute onset of symptoms and had previously been quite well were admitted to the study. Patients suffering from measles, malnutrition, or malaria were excluded. Similarly, patients with features of the nephrotic syndrome, such as massive albuminuria, hypoalbuminaemia, and hypercholesterolaemia, were also excluded. On admission a history of recent throat or skin infection was sought, and the clinical findings were carefully recorded. Special attention was given to the presence or absence of signs of volume overload, azotaemia, hypertension, and neurological deficit. The clinical course of the disease was carefully assessed throughout the patient's stay in hospital.

Severity of illness For each patient, severity of disease at the time of collection of each blood sample was assessed as follows:

$$
\begin{array}{lll}
\text { mild } & - & \text { blood urea less than } 10 \mathrm{mmol} / \mathrm{l} \\
\text { moderate } & -- & \text { blood urea } 10-20 \mathrm{mmol} / 1 \\
\text { severe } & - & \text { blood urea above } 20 \mathrm{mmol} / \mathrm{l}
\end{array}
$$

In all, 86 samples were collected from the patients at various stages of the disease, 56 of which were taken in the oliguric phase. Oliguria was defined as a 24hour urinary output of less than $500 \mathrm{ml}$ for children under 5 years and $600 \mathrm{ml}$ for children over 5 years.

Blood and urine samples On admission blood samples were collected for immune complex, C3, C4, and factor B estimations, as well as for serum electrolytes and urea. Other investigations included determination of anti streptolysin O (ASO) titre, serum proteins and cholesterol, and blood film for malaria parasites. Subsequent samples were collected on alternate days during the patient's stay in hospital and at follow-up three months later. Storage of sera was at $-20^{\circ} \mathrm{C}$ in small aliquots, which were thawed only once before use. All sera for complement estimations were collected in bottles containing EDTA. Urine samples were collected for microscopy and culture.

METHODS Complement levels were determined by the single radial immunodiffusion method of Mancini et al. (1965), using monospecific antisera to C3, C4, and factor B. Soluble immune complexes were detected by two methods: the radiobioassay method using guinea-pig macrophages (Onyewotu et al., 1974), and an anti-complementary method modified from that of Mowbray et al. (1973), using ${ }^{51} \mathrm{Cr}$-labelled sheep red cells. All sera were inacti- vated by heating at $56^{\circ} \mathrm{C}$ for 30 minutes before testing for anti-complementary activity.

Material obtained from skin vesicles by aspiration with a fine hypodermic needle (No. 23), or by a swab, was moistened with sterile normal saline and plated immediately onto blood agar. The plates were incubated for 24 hours, after which streptococci were identified by their haemolytic and colonial characteristics. ASO titres were determined by a microtitre method using a commercial kit obtained from Wellcome Reagents Limited.

Aetiology of nephritis Throat swabs were positive for $\beta$-haemolytic streptococci in six patients who all had ASO titres of 1:200 and above. Streptococci were isolated from skin lesions in nine patients, only three of whom had a raised ASO titre. Streptococcal infection was not proved in the remaining nine patients although all had a history of recent skin infection. DNAse B titres could not be determined.

\section{Results}

IMMUNE COMPLEXES IN ACUTE NEPHRITIS AND PYODERMA

Figure 1 shows the levels of soluble complexes detected by the radiobioassay method on 24 samples taken from patients with AGN on admission to

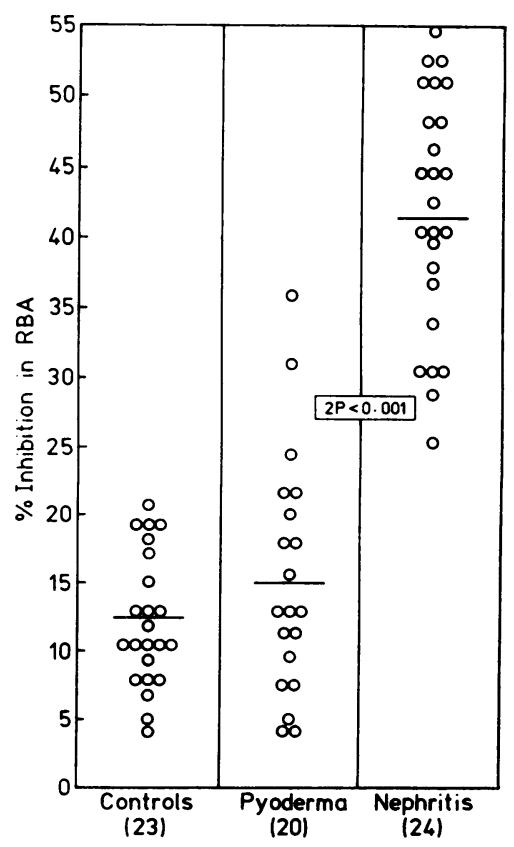

Fig. 1 Immune complex estimation in patients with acute poststreptococcal nephritis and pyoderma, and controls. 
hospital, compared with those detected in 20 children with pyoderma without nephritis, and 23 healthy control children. There was a significant difference between the nephritis and pyoderma cases $(2 \mathrm{P}<$ 0.001 ). Similar results were obtained with the anticomplementary assay. In 67 samples tested by both methods, a good correlation was obtained (Fig 2). There was no difference between the levels of circulating complexes detected in the throat-associated and skin-associated forms of the disease. All the patients subsequently recovered, and the investigations, including immune complexes, carried out on samples taken at follow-up three months later gave normal results-all were within $\pm 2 \mathrm{SD}$ of the mean obtained in the control samples.

\section{IMMUNE COMPLEXES IN RELATION TO}

DISEASE SEVERITY

Figure 3 shows the levels of soluble complexes detected by RBA in 56 sera obtained from patients in the oliguric phase of $A G N$, in relation to disease severity recorded. Thirty-five of these were from patients with mild disease, 16 from patients with moderately severe disease, and five from cases of severe disease. Blood urea values in the oliguric phase correlated quite well with immune complex levels $(r=+0 \cdot 76,2 \mathrm{P}<0.001)$.

SERIAL IMMUNE COMPLEXES IN RELATION TO CLINICAL COURSE OF AGN

In two patients, initially classified on admission as

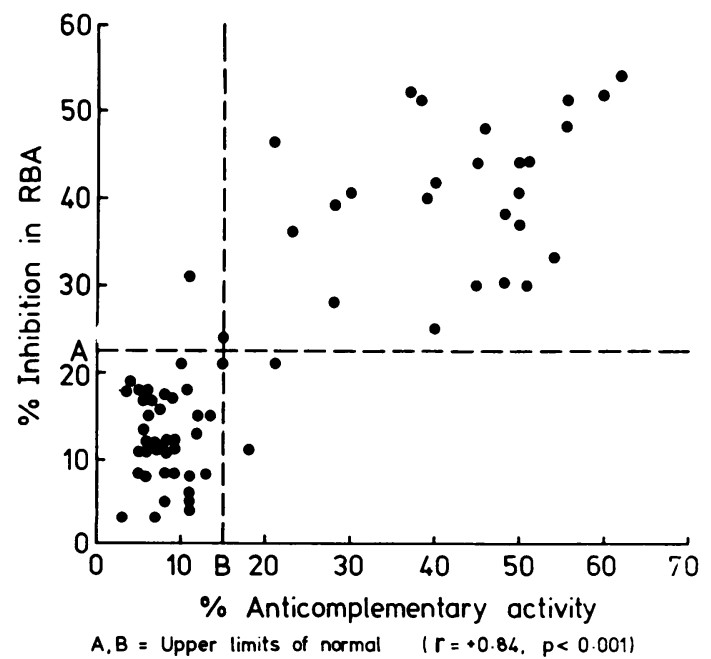

Fig. 2 Results of immune complex estimation by the radiobioassay $(R B A)$ and anticomplementary methods on 67 sera from patients with acute nephritis (24), pyoderma (20), and controls (23).

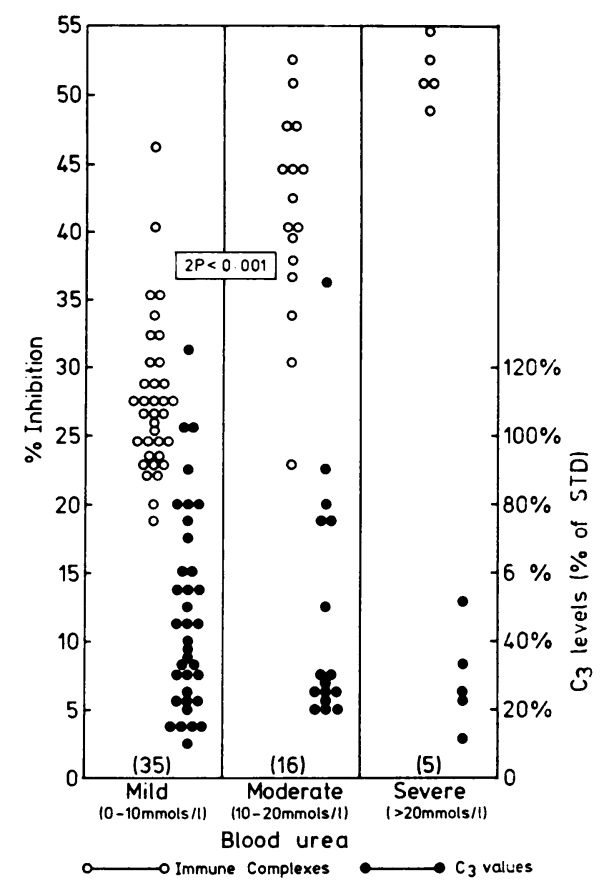

Fig. 3 Immune complex and $C_{3}$ levels in relation to disease severity as judged by blood urea values.

having mild disease, urinary output dropped and blood urea increased while they were in hospital. One of them became completely anuric on the sixth day. In both patients, immune complexes steadily increased in amount as urinary output fell (Fig 4).

\section{COMPLEMENT LEVELS IN NEPHRITIS AND PYODERMA}

The Table shows mean C3, C4, and factor B levels in

Table Complement levels in patients with nephritis and pyoderma and controls

\begin{tabular}{lllll}
\hline Complement & $\begin{array}{l}\text { Nephritis } \\
(\mathrm{n}=24)\end{array}$ & $\begin{array}{l}\text { Pyoderma } \\
(\mathrm{n}=20)\end{array}$ & $\begin{array}{l}\text { Controls } \\
(\mathrm{n}=23)\end{array}$ \\
\cline { 2 - 5 } & Acute & Recovered & & \\
\hline C3 (\% of Std) & $56 \pm 31$ & $145 \pm 61$ & $140 \pm 36$ & $160 \pm 58$ \\
$\begin{array}{l}\text { C4 (\% of Std) } \\
\text { Factor B } \\
\text { (\% of Std) }\end{array}$ & $138 \pm 38$ & $128 \pm 42$ & $128 \pm 29$ & $132 \pm 36$ \\
\hline
\end{tabular}

samples taken from patients with AGN on admission and three months later, and from cases of pyoderma, and the healthy controls. Only one patient had a low C4 value (less than mean C4 minus 2 SD of normal control values). This patient was probably seen quite early in the course of his disease. Fifty of the 56 samples $(90 \%)$ collected in the oliguric phase showed 


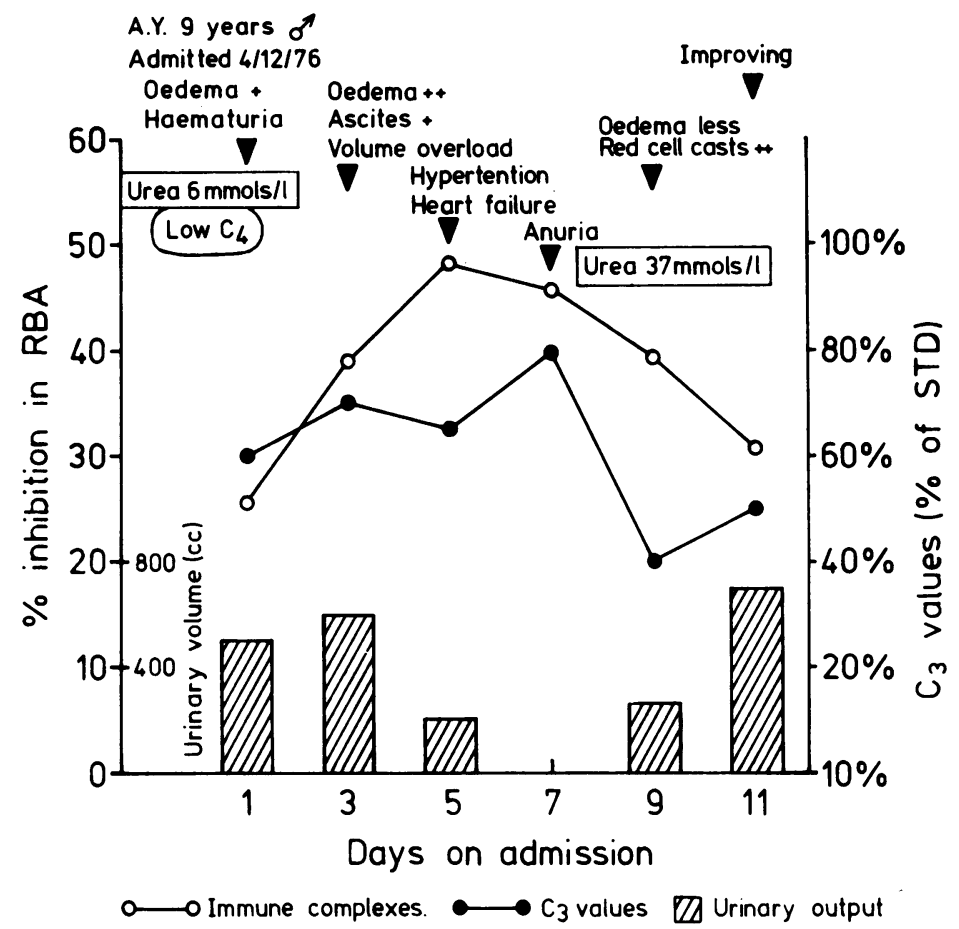

Fig. 4 Serial immune complex and $C_{3}$ levels in a patient admitted with apparently mild disease, who later deteriorated.

low factor B levels (less than mean minus 2SD of normal control values). There was no correlation between $\mathrm{C} 3$ levels and blood urea values, nor did serial $\mathrm{C} 3$ determinations prove useful in predicting onset of anuria in the two patients who deteriorated while in hospital.

\section{Discussion}

Although poststreptococcal AGN is generally regarded as an immune complex disease, mainly from evidence obtained from immunofluorescent studies on renal tissue, reports of soluble complexes detected in this disease are surprisingly few. Moreover, no previous attempts have been made to relate levels of complexes detected to disease activity. Our results using two different methods, which showed a good correlation with each other, confirm that soluble complexes are indeed present in acute poststreptococcal AGN. The possibility that the activity of $\mathrm{C} 3 \mathrm{NeF}$ was being measured in the anticomplementary test was excluded by the fact that all sera used in this test were heat-inactivated, since $\mathrm{C} 3 \mathrm{NeF}$ is heat-labile (Pickering et al., 1968; Thompson, 1977).

The extent to which immune complexes were responsible for the low $\mathrm{C} 3$ values usually observed in AGN is uncertain in view of the fact that normal values of the earlier components of complement, such as $\mathrm{Clq}$ and $\mathrm{C} 4$, have consistently been reported. Kohler and ten Bensel (1969) suggest that normal C4 values may be attributed to masking of increased catabolism by increased synthesis of $\mathrm{C} 4$. It is, therefore, likely that only transient $\mathrm{C} 4$ depression occurs in poststreptococcal AGN as compared with other immune complex nephritides, such as lupus nephritis, and that this may be related to the favourable prognosis often seen in this disease. All our patients recovered completely. Immune complexes were not detected in any of the follow-up samples taken at three months, and results of other investigations were normal. These confirm the observations of Cameron et al. (1973) that C3 levels usually return to normal in eight weeks if the initial disease was AGN, and tend to persist for longer periods at low levels in cases of MCGN.

The low levels of factor B observed in most of our patients are consistent with the view that their low C3 levels were due to complement activation by the alternate pathway, presumably by $\mathrm{C} 3 \mathrm{NeF}$. However, there are two possible alternative mechanisms for the lowering of factor $B$ concentrations in these patients. The first is that, when the classical pathway is activated, $\mathrm{C} 3 \mathrm{~b}$ is produced; and via the $\mathrm{C} 3 \mathrm{~b}$ feedback mechanism the alternate pathway convertase, $\mathrm{C} 3 \mathrm{bBb}$, is produced. The resultant levels of $\mathrm{C} 4$ and 
factor B will depend not only upon the degree of depletion but also on the ability of the synthetic processes for each. Secondly, factor B is a rather small molecule and is readily lost in the urine. We did not quantitate proteinuria in our patients, and it is possible that if this were done a correlation might be demonstrated between the degree of proteinuria and the levels of factor B.

The duration and degree of urinary suppression and azotaemia have previously been shown to be related to the clinical picture of AGN (Lancet, 1964). More recently, a group of French workers have attempted to match renal histological findings with clinical severity of AGN (Hinglais et al., 1974). In general, persistent abnormalities of renal function occurred in patients with the more severe histological changes, such as crescent formation. Our results indicate that a significant correlation exists between the degree of azotaemia and levels of circulating immune complexes detected, and lends support to the view that AGN is an immune complex disease. It will be interesting to see whether any such correlation can be demonstrated between histological findings in our patients and the amount of soluble complexes in the circulation. This study is currently in progress.

Serial estimation of soluble complexes proved more useful than serial C3 in predicting the onset of anuria in the two patients admitted with apparently mild disease who later deteriorated. The fact that $\mathrm{C} 4$ in one of these patients was low only in the sample taken on admission suggests that $\mathrm{C4}$ depression occurs quite early in the course of the disease. Serial immune complex estimation on sera from patients with poststreptococcal AGN may be of value in monitoring the progress of patients with this disease.

We are grateful to Drs Brian Greenwood and Hilton Whittle for helpful suggestions and advice, and to the Medical Research Council of the United Kingdom for the research facilities provided. We also thank Professor Richard Dobbs for allowing us to study patients under his care, and Professor Egler for the cooperation received from the staff of the Microbiology Department.

\section{References}

Alper, C. A., Levin, A. S., and Rosen, F. S. (1966). Beta1c-globulin: metabolism in glomerulonephritis. Science 153, 180-182.

Amos, N., Sissons, J. G. P., Girard, J. F., Lachmann, P. J., and Peters, D. K. (1976). The cofactors required by $\mathrm{C} 3$ nephritic factor to generate a C3 convertase in vitro. Clinical and Experimental Immunology, 24, 474-482.

Andres, G. A., Accinni, L., Hsu, K. C., Zabriskie, J. B., and Seegal, B. C. (1966). Electron microscopic studies of human glomerulonephritis with ferritin-conjugated antibody. Journal of Experimental Medicine, 123, 399412.

Anthony, B. F., Kaplan, E. L., Chapman, S. S., Quie, P. G., and Wannamaker, L. W. (1967). Epidemic acute nephritis with reappearance of type-49 streptococcus. Lancet, 2, 787-790.

Bergner-Rabinowitz, S., Ofek, I., Fleiderman, S., Zohar, M., Rabinowitz, K., and Ginsburg, I. (1973). Evaluation of streptozyme and antistreptolysin 0 tests in streptococcal pyodermal nephritis. Applied Microbiology, 26, 56-58.

Cameron, J. S., Vick, R. M., Ogg, C. S., Seymour, W. M., Chantler, C., and Turner, D. R. (1973). Plasma C3 and C4 concentrations in management of glomerulonephritis. British Medical Journal, 3, 668-672.

Dillon, H. C., Jr. (1970). Streptococcal skin infection and acute glomerulonephritis. Postgraduate Medical Journal, 46, 641-652.

Hinglais, N., Garcia-Torres, R., and Kleinknecht, D. (1974). Long-term prognosis in acute glomerulonephritis. The predictive value of early clinical and pathologic features observed in 65 patients. American Journal of Medicine, 56, 52-60.

Kaplan, E. L., Anthony, B. F., Chapman, S. S., Ayoub, E. M., and Wannamaker, L. W. (1970). The influence of the site of infection on the immune response to group A streptococci. Journal of Clinical Investigation, 49, $1405-1414$.

Koffler, D., Schur, P. H., and Kunkel, H. G. (1967). Immunological studies concerning the nephritis of systemic lupus erythematosus. Journal of Experimental Medicine, 126, 607-624.

Kohler, P. F., and ten Bensel, R. (1969). Serial complement component alterations in acute glomerulonephritis and systemic lupus erythematosus. Clinical and Experimental Immunology, 4, 191-202.

Krishnan, C., and Kaplan, M. H. (1967). Immunopathologic studies of systemic lupus erythematosus II. Antinuclear reaction of gamma-globulin eluted from homogenates and isolated glomeruli of kidneys from patients with lupus nephritis. Journal of Clinical Investigation, 46, 569-579.

Lancet (1964). Oliguric acute glomerulonephritis (Editorial). Lancet, 2, 1429.

Lewis, E. J., Carpenter, C. B., and Schur, P. H. (1971). Serum complement component levels in human glomerulonephritis. Annals of Internal Medicine, 75, 555-560.

McIntosh, R. M., Kaufman, D. B., Kulvinskas, C., and Grossman, B. J. (1970). Cryoglobulins. I. Studies on the nature, incidence, and clinical significance of serum cryoproteins in glomerulonephritis. Journal of Laboratory and Clinical Medicine, 75, 566-577.

Mancini, G., Carbonara, A. O., and Heremans, J. F. (1965). Immunochemical quantitation of antigens by single radial immunodiffusion. Immunochemistry, 2 , 235-254.

Mohammed, I., Ansell, B. M., Holborow, E. J., and Bryceson, A. D. M. (1977). Circulating immune complexes in subacute infective endocarditis and post- 
streptococcal glomerulonephritis. Journal of Clinical Pathology, 30, 308-311.

Mowbray, J. F., Hoffbrand, A. V., Holborow, E. J., Seah, P. P., and Fry, L. (1973). Circulating immune complexes in dermatitis herpetiformis. Lancet, 1, 400-402.

Onyewotu, I. I., Holborow, E. J., and Johnson, G. D. (1974). Detection and radioassay of soluble circulating immune complexes using guinea pig peritoneal exudate cells. Nature, 248, 156-159.

Pickering, R. J., Gewurz, H., and Good, R. A. (1968). Complement inactivation by serum from patients with acute and hypocomplementemic chronic glomerulonephritis. Journal of Laboratory and Clinical Medicine 72, 298-307.

Potter, E. V., Siegel, A. C., Simon, N. M., McAninch, J., Earle, D. P., Poon-King, T., Mohammed, I., and Abidh, S. (1968). Streptococcal infections and epidemic acute glomerulonephritis in South Trinidad. Journal of Paediatrics, 72, 871-884.

Schreiber, R. D., Medicus, R. G., Götze, O., and Müller-Eberhard, H. J. (1975). Properdin-and Nephritic Factor-dependent C3 convertases: requirement of native $\mathrm{C} 3$ for enzyme formation, and the function of bound $\mathrm{C} 3 \mathrm{~b}$ as properdin receptor. Journal of Experimental Medicine, 142, 760-772.
Sobel, A., Gabay, Y., and Lagrue, G. (1976). Recherche de complexes immuns circulants par le test de déviation de la fraction Clq du complément. Premières applications à l'étude des glomerulopathies humaines. Nouvelle Presse Médicale, 5, 1465-1469.

Thompson, R. A. (1977). Complement in perspective. In Immunology in Medicine, edited by E. J. Holborow and W. G. Reeves, p. 191. Academic Press, London; Grune and Stratton, New York.

Whittle, H. C., Abdullahi, M. T., Fakunle, F., Parry, E. H. O., and Rajkovic, A. D. (1973). Scabies, pyoderma, and nephritis in Zaria, Nigeria. A clinical and epidemiological study. Transactions of the Royal Society of Tropical Medicine and Hygiene, 67, 349-363.

Williams, D. G., Peters, D. K., Fallows, J., Petrie, A., Kourilsky, O., Morel-Maroger, L., and Cameron, J. S. (1974). Studies of serum complement in the hypocomplementaemic nephritides. Clinical and Experimental Immunology, 18, 391-405.

Zabriskie, J. B. (1971). The role of streptococci in human glomerulonephritis. Journal of Experimental Medicine, 134, 180s-192s.

Requests for reprints to: Dr I. I. Onyewotu, Department of Medicine, Ahmadu Bello University Hospital, Zaria, Nigeria. 